\title{
Simplified restriction endonuclease method for typing and subtyping adenoviruses
}

\author{
JM DARVILLE \\ From the University of Bristol Medical School, Department of Virology, Bristol Royal Infurmary, Bristol
}

SUMMARY Restriction endonuclease digestion of viral DNA labelled in vivo with phosphorus-32 has been used to type and to subtype both conventional and enteric adenoviruses. The method is a modification of that already described for typing and subtyping herpes simplex virus and, like the latter, needs far less material than methods previously described.

The lack of serological variants of the herpes viruses (herpes simplex virus types 1 and 2, varicella-zoster virus, and cytomegalovirus) has meant that the detailed characterisation of subtypes of these viruses and, therefore, the full study of their epidemiology, has been delayed until the development of molecular techniques such as restriction endonuclease analysis. ${ }^{1-3}$

There are 40 known serotypes of human adenovirus forming subgroups $A$ (types 12,18 , and $31), B(3,7,11,14,16,21,34$, and 35$), C(1,2,5$, and 6$), \mathrm{D}(8,9,10,13,15,17,19,20,22-30,32$, $33,36,37$, and 39$), E(4), F(40)$, and $G(41)^{45}$ according to their oncogenicity for newborn hamsters and to the characterisation of their DNA.

Because of this large number of serotypes adenovirus epidemiology has not been subject to the same degree of constraint as that of the herpes viruses. Nevertheless, the value of serological techniques in studying the epidemiology of these viruses is limited by the fact that serotypic intermediates occur, ${ }^{6}$ as do intertypic recombinants, ${ }^{7}$ at least experimentally. Furthermore, restriction endonuclease analysis has shown within single adenovirus serotypes the existence of intratypic variants of genome types, ${ }^{8}$ which have stable and distinct electrophoretic profiles. This technique has been used to demonstrate subtypes of several serotypes, ${ }^{51011}$ thus aiding the study of the epidemiology of the virus. These studies, however, have relied on large scale virus cultures ${ }^{12}$ and the purification of virus particles $^{11}$ and, although good results have been achieved, the methods used are too demanding in resources and too lengthy for use in a routine laboratory.

Accepted for publication 22 October 1984
This paper reports the successful adaptation for the subtyping of adenoviruses of a restriction endonuclease analysis method already developed in this laboratory for typing and subtyping herpes simplex virus. ${ }^{13}$

\section{Material and methods}

\section{VIRUSES}

Standard strains of adenoviruses were obtained from the Virus Reference Laboratory, Central Public Health Laboratory, London. Other adenoviruses were isolated in our laboratory from clinical specimens and were typed by neutralisation or by immune electron microscopy in a method derived from that of Svensson and von Bonsdorff. ${ }^{14}$ An enteric adenovirus was kindly provided by $\mathrm{Dr}$ CR Madeley of the Royal Victoria Infirmary, Newcastle upon Tyne.

\section{RESTRICTION ANALYSIS}

The experimental procedure is essentially as reported previously, ${ }^{13}$ although there are some variations in detail which are outlined in the description of the method given below.

Adenoviruses to be analysed are harvested by freezing and thawing when their cultures show complete or near complete cytopathic effect on primary isolation or on passage. Each virus isolate is inoculated $(10 \mu \mathrm{l})$ into one well of a microculture plate (Linbro) containing 293 cells $^{15}$ (Flow) (about 0.25 $\mathrm{cm}^{2}$ or $10^{5}$ cells), which have been incubated in phosphate free medium. These cells have been introduced for the routine isolation of conventional adenoviruses $^{16}$ and readily support the growth of enteric adenovirus. ${ }^{17}$ Human embryo kidney (HEK) cells and HEp- 2 cells may also be used. After 1 h 60 $\mu l$ of phosphate free medium is added and after a 
further $2 \mathrm{~h}$ the inoculum is removed and replaced with $75 \mu$ l of phosphate free medium containing $7 \cdot 5$ $\mu \mathrm{Ci}^{32} \mathbf{P}$ (orthophosphate in dilute $\mathrm{HCl}$, Amersham).

After three or four days, when the cytopathic effect is total or near total, the DNA is extracted with sodium dodecyl sulphate $(5 \% \mathrm{wt} / \mathrm{vol})$ and phenol (chromatography grade, $\mathrm{BDH}$; saturated with $20 \mathrm{mmol} / 1 \mathrm{Tris}, 75 \mathrm{mmol} / \mathrm{l} \mathrm{NaCl}$, and $50 \mathrm{mmol} / \mathrm{l}$ edetic acid), precipitated with ethanol, and resuspended in $170 \mu \mathrm{l}$ of dilute RNA-ase $(50 \mu \mathrm{g} / \mathrm{ml}$ RNA-ase A, 250 units/ml RNA-ase $T_{1}$; Sigma). The ${ }^{32} \mathrm{P}$ content of the DNA is estimated by use of a Mini-Monitor contamination meter (MiniInstruments Ltd).

Reaction mixtures are set up in sterile round bottomed microtitre plates (Flow) in a final volume of $50 \mu \mathrm{l}$. The mixtures consist of 2 units of restriction

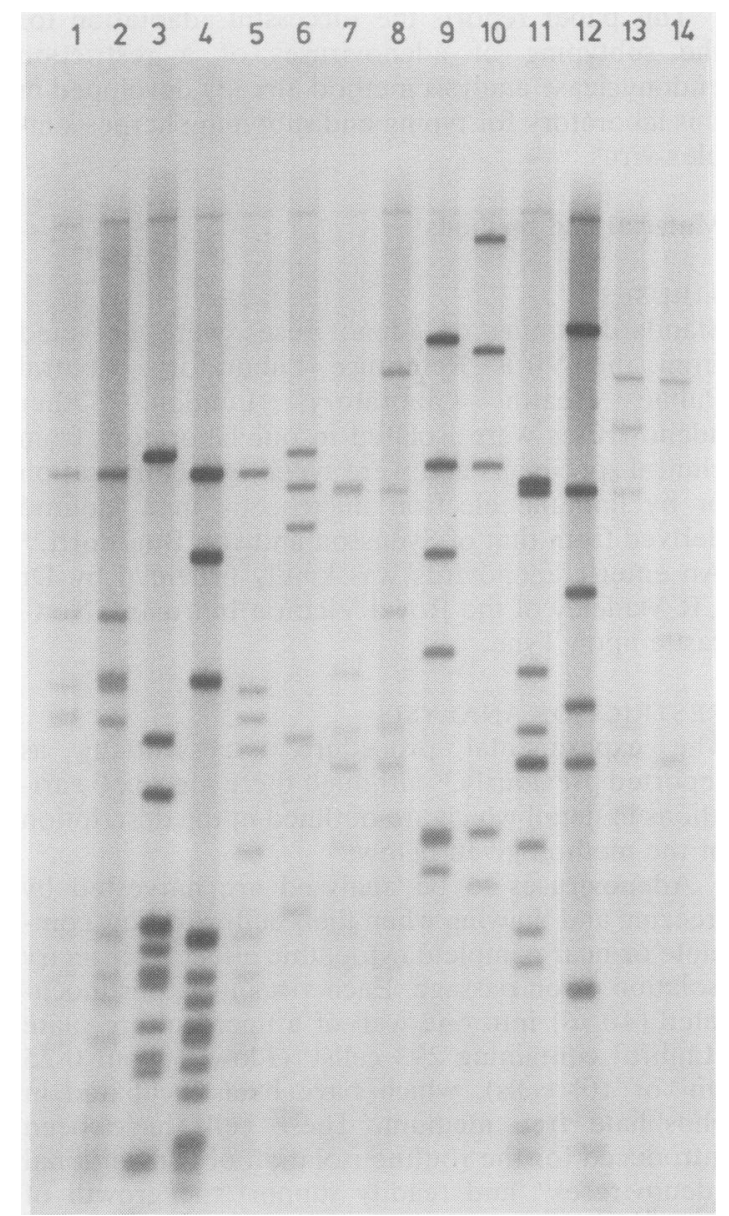

Fig. 1 Tracks 1 to 14 are $P v u$ II restriction endonuclease profiles of adenovirus types $1,2,4,5,6,7,9,10,11,14,15$, 31 , "10/19" and an enteric adenovirus. enzyme, $40 \mu \mathrm{l}$ of DNA solution, and $8 \mu \mathrm{l}$ of restriction buffer, the final concentrations of which are 6 $\mathrm{mmol} / \mathrm{l}$ of Tris $\mathrm{HCl}(\mathrm{pH} \mathrm{7 \cdot 5}), 6 \mathrm{mmol} / \mathrm{l}$ of $\mathrm{MgCl}_{2}, 6$ $\mathrm{mmol} / \mathrm{l}$ of B-mercaptoethanol, and $800 \mathrm{mg} / \mathrm{ml}$ of nuclease free bovine serum albumin (Sigma). Three digests may be made from each DNA harvest, and while many enzymes are used for analysing adenoviruses those used in this study were Pvu II and Bgl II (Bethesda Research Laboratories) and Sst I and Pst I (Cambridge Biotechnology Laboratories).

The mixtures are incubated for $3-4 \mathrm{~h}$ at $37^{\circ} \mathrm{C}$ and the reactions stopped with $6 \mu \mathrm{l}$ of $100 \mathrm{mmol} / \mathrm{l}$ edetic acid containing $10 \%$ Ficoll 400 (Sigma) and bromophenol blue. The resultant DNA fragments are resolved by overnight horizontal agarose gel electrophoresis at $2 \mathrm{~V} / \mathrm{cm}$. The gels are air dried $\left(90^{\circ}\right)$ and then autoradiographed.

For successful resolution of the smaller fragments from the relatively small adenovirus genome, polyacrylamide gel electrophoresis (PAGE) may also been used. Good differentiation of adenovirus subtypes may usually be achieved, however, with only the agarose gel and no PAGE results are presented here.

To test the stability of the adenovirus genome in cell culture and to look for interactions between infecting virus and the fragment of adenovirus type 5 genome in 293 cells restriction enzyme analysis was performed on isolates of adenovirus types 3 and 4 before and after six passages in 293 and HEp-2 cells. As a further test for interactions with the adenovirus type 5 fragment restriction profiles of adenovirus types 3, 4, and 5 labelled in 293, HEK, and HEp- 2 cells were compared. Furthermore, DNA from uninfected cells was analysed in the same way as that from virus infected cells.

\section{Results}

Fig. 1 is an autoradiograph of the Pvu II profiles of the DNAs from 14 serotypes of adenovirus; these are types $1,2,4,5,6,7,9,10,11,14,15,31$, "10/19", and an enteric adenovirus. The " $10 / 19 "$ isolate (track 13), which was from an ocular specimen, had a restriction profile almost indistinguishable from that of a standard type 37 (unpublished observation). In all tracks there is a relatively faint band of high molecular weight which is probably of non-viral origin. There are striking similarities between the profiles of types 1 and 2 (tracks 1 and 2) and to a lesser extent between these and types 5 and 6 (tracks 4 and 5), all four of which are in adenovirus subgroup C. Again, similar profiles are seen with types 9,10 , and 15 (tracks 7,8 , and 11) in subgroup D. In contrast, while two of the represen- 


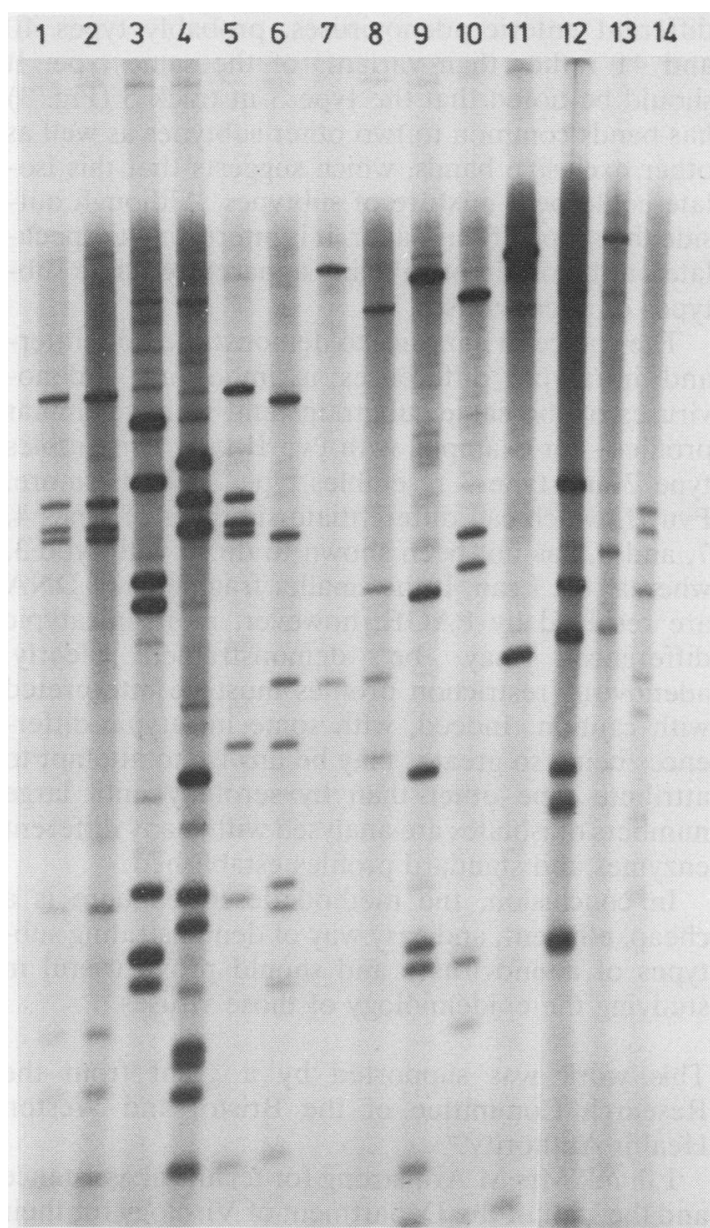

Fig. 2 Tracks 1 to 14 are Bgl II restriction endonuclease profiles of adenovirus types $1,2,4,5,6,7,9,10,11,14,15$, 31 , "10/19" and an enteric adenovirus.

tatives of subgroup B (types 11 and 14 in tracks 9 and 10) are similar, the third (type 7 in track 6) is not.

Fig. 2 shows the profiles of the same adenovirus strains as in Fig. 1 when digested with Bgl II. As in Fig. 1 all tracks show a faint high molecular weight band, and in most of the tracks faint bands due to incomplete digestion are visible. Again, some similarities may be seen between the profiles of some of the members of the same subgroup.

In Fig. 3 the profiles are presented as tracings in order to compensate for the running of digests on different gels, for different track lengths, and for the exposure and development to different intensities. The first track shows the common profile of all type 3 adenoviruses analysed with Pvu II, while the next four tracks show the distinct profiles of four unre- lated isolates of this type analysed with Sst I. The next three tracks are Pvu II profiles of three clinical isolates of adenovirus type 4 . The next three are Pvu II profiles of reference strains of types 7 and $7 a$ and of a recent laboratory isolate of type 7 , the former showing much similarity with its fellow sub-group B member, type 3 . Then follow two profiles of type 8 which vary little. Finally, there are profiles of two enteric adenoviruses, and while it is not clear whether these are different serotypes or variants of the same serotype a comparison of their Sma I profiles (unpublished observations) with those published by Kidd et al $^{12}$ indicates that they are types 40 and 41 respectively.

The restriction of labelled but uninfected 293 cells sometimes gives rise to a single high molecular weight band such as is seen in Figs. 1 and 2, but on other occasions no bands are seen. At no time have any bands been seen in digests of uninfected cells which could be confused with bands from adenovirus infected cells.

The passage of types 3 and 4 through 293 cells or HEp-2 cells did not result in any detectable changes in restriction profiles. The profiles of types 3,4, and 5 were identical whether virus was labelled in 293 , HEp-2, or HEK cells.

$$
\begin{aligned}
& \begin{array}{lllllllllllllll}
3 & 3 & 3 & 3 & 3 & 4 & 4 & 4 & 7 & 7 & 7 & 8 & 8 & 40 & 41
\end{array} \\
& ---
\end{aligned}
$$

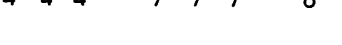

$$
\begin{aligned}
& -
\end{aligned}
$$

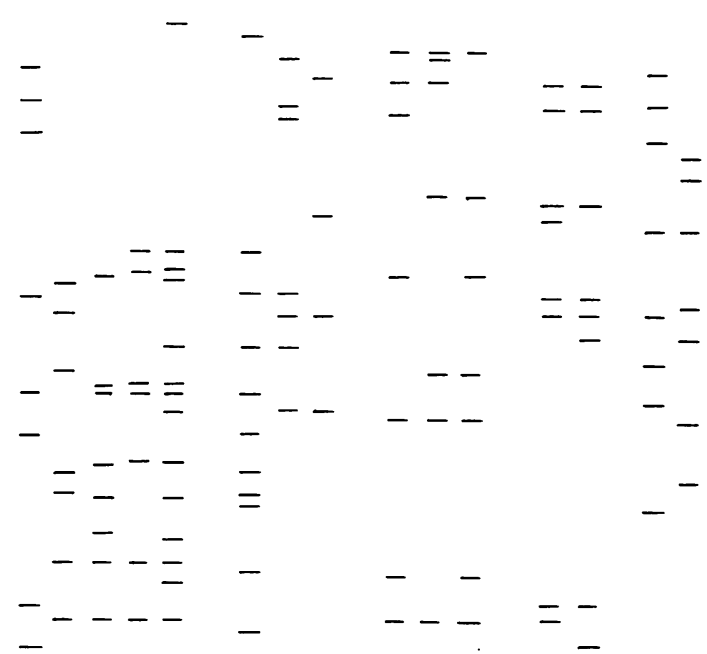

Fig. 3 Restriction endonuclease profiles of selected adenovirus serotypes are presented as tracings. Shown here are five profiles of adenovirus type 3 (the common Pvu II profile followed by four distinct Sst II profiles), three Pvu II profiles of adenovirus type 4, three Pvu II profiles of adenovirus type 7 (7 and 7a type strains and one clinical isolate), two Pvu II profiles of adenovirus type 8, and two Pst I profiles of enteric adenovinuses. 


\section{Discussion}

The value of restriction endonuclease analysis in the characterisation of subtypes of adenoviruses has already been shown. ${ }^{58-11}$ Published procedures for this analysis are complex, however, and in order to make the technique more suitable for use in routine laboratories it is necessary to miniaturise and simplify the procedures making analysis cheaper and easier to perform. Such a modification is described in this paper.

The choice of 293 cells for labelling is determined by their requirement for the growth of the hitherto uncultivable enteric adenoviruses ${ }^{17}$ and by their ability to grow adenovirus type 8 more quickly than cells other than HEK cells (Dr APCH Roome, personal communication). For other adenoviruses HEp-2 cells were satisfactory, but for convenience the single cell line is usually used. Despite the long and variable time taken for the adenoviral cytopathic effect to appear on primary isolation, a period of three to four days is nearly always adequate for the production of a sufficient amount of labelled DNA, whether conventional or enteric adenoviruses are being analysed.

A possible objection to the use of 293 cells is their possession of a fragment of the adenovirus type 5 genome which might interact with the DNA of an infecting virus. It was not shown, however, either by serial passage in 293 cells or by the comparison of profiles of DNA labelled in 293 cells with that labelled in HEp- 2 or HEK cells that this type 5 fragment altered the restriction profile. In some circumstances a high molecular weight band may be seen, and since this is also seen in profiles of uninfected cells it must be of cellular (or contaminant) origin. This, however, is always much fainter than bands of viral origin. Another problem, but again one which is obvious and easy to correct, is the production of bands from incomplete digests when too much DNA or too little enzyme is added to the restriction mixtures.

The use of restriction endonuclease subtyping for viral epidemiology relies on the profiles being stable with passage. While the effects of long term in vivo passage are unknown, selected adenoviruses were stable during six in vitro passages (unpublished observations), and it has been shown that at low multiplicity of infection adenovirus type 16 remains identical with its prototype after 22 in vitro passages (Professor G Wadell, personal communication).

In this paper restriction profiles of 16 adenovirus serotypes are illustrated. In addition to these, profiles have been obtained in this laboratory for types $13,16,17,19,30,31$, and 37 . Intratypic variants of types $3,4,7$, and 8 are shown as are two different enteric adenoviruses, probably types 40 and 41 rather than variants of the same type. It should be noted that the type 3 in track 5 (Fig. 3) has bands common to two other subtypes as well as other exclusive bands, which suggests that this isolate could be a mixture of subtypes. Although outside the scope of this paper, it is interesting to speculate on the origin of so many apparently stable subtypes of adenoviruses.

The choice of enzymes to demonstrate both interand intratypic differences is important. Adenoviruses of the same subgroup tend to have similar profiles - for example, with Pvu II type 1 resembles type 2 and type 3 resembles type 7 . Furthermore, Pvu II, which can differentiate subtypes of types 4 , 7 , and 8 , has not been shown to do so with type 3 , whereas Sst I can. If the smaller fragments of DNA are resolved by PAGE, however, more intratypic differences may be demonstrable. Clearly, adenovirus restriction profiles must be interpreted with caution. Indeed, with some intratypic differences being so great it may be unwise to attempt to attribute type other than by serology until large numbers of isolates are analysed with many different enzymes and standard profiles established.

In conclusion, the method described here is a cheap, efficient, and easy way of demonstrating subtypes of adenoviruses and should prove useful in studying the epidemiology of those viruses.

This work was supported by a grant from the Research Committee of the Bristol and Weston Health Authority.

I thank Mrs M Armstrong for technical assistance and the staff of the Department of Virology for their help.

\section{References}

'Tullo AB, Shimeld C, Easty DL, Darville JM. Distribution of latent herpes simplex virus infection in the human trigeminal ganglion. Lancet 1983; 353.

${ }^{2}$ Pichini B, Ecker JR, Grose C, Hyman RW. DNA mapping of paired varicella-zoster virus isolates from patients with shingles. Lancet 1983;ii: 1223-5.

${ }^{3}$ Spector SA. Transmission of cytomegalovirus among infants in hospital documented by restriction-endonuclease-digestion analyses. Lancet $1983 ; \mathrm{i}: 378-81$.

4 Wadell G. Adenoviruses. In: Lycke E, Norrby E, eds. Textbook of medical virology. London: Butterworths, 1983:286-92.

$s$ Kidd AH. Genome variants of adenovirus 41 (subgroup G) from children with diarrhoea in South Africa. J Med Virol 1984; 14:49-59.

- Wigand R, Fliedner D. Serological intermediate adenovirus strains: A regular feature of group II adenoviruses. Arch Ges Virusforsch 1968;24:245-56.

' Sambrook J, Williams J, Sharp PA, Grodzicker T. Physical mapping of temperatue-sensitive mutations of adenoviruses. $\mathrm{J} \mathrm{Mol}$ Biol 1975;97:369-90. 
${ }^{8}$ Wadell G, Hammarskjöld M-L, Winberg G, Varsanyi TM, Sundell G. Genetic variability of adenoviruses. Ann NY Acad Sci 1980;354:16-42.

- Wadell G, Varsanyi TM. Demonstration of three different subtypes of adenovirus type 7 by DNA restriction site mapping. Infect Immun 1978; 21:238-46.

${ }^{10}$ Wadell G, de Jong JC, Wolontis S. Molecular epidemiology of adenoviruses: Alternating appearance of two different genome types of adenovirus 7 during epidemic outbreaks in Europe from 1958-80. Infect Immun 1981;34:368-72.

"Wadell G, de Jong JC. Restriction endonucleases in identification of a genome type of adenovirus 19 associated with keratoconjunctivitis. Infect Immun 1980;27:292-6.

${ }^{12}$ Kidd AH, Banatvala JE, de Jong JC. Antibodies to fastidious faecal adenoviruses (species 40 and 41 ) in sera from children. $J$ Med Virol 1983;11:333-41.

${ }^{13}$ Darville JM. A miniaturised and simplified technique for typing and subtyping herpes simplex virus. J Clin Pathol 1983; 36:929-34.
14 Svensson L, von Bonsdorff C-H. Solid-phase immune electron microscopy (SPIEM) by use of protein $\mathrm{A}$ and its application for characterisation of selected adenovirus serotypes. J Med Virol 1982; 10:243-53.

is Graham FL, Smiley J, Russell WC, Nairn R. Characteristics of a human cell line transformed by DNA from human adenovirus type 5. J Gen Virol 1977;36:59-72.

16 Yirrell DL, Roome APCH, Darville JM, Ashley CR, Harbour J. Comparison of the continuous cell line 293 human embryo kidney cells and human embryo fibroblast cells for the cultivation of ocular viruses. J Clin Pathol 1983;36:996-9.

${ }^{17}$ Takiff HE, Straus SE, Garon CF. Propagation and in vitro studies of previously non-cultivable enteral adenoviruses in 293 cells. Lancet $1981 ;$ ii:832-4.

Requests for reprints to: Dr JM Darville, Department of Virology, Bristol Royal Infirmary, Marlborough Street, Bristol BS2 8HW, England. 